\title{
Evaluation of Integrated Multisatellite Retrievals for GPM (IMERG) over Southern Canada against Ground Precipitation Observations: A Preliminary Assessment ${ }^{\mathscr{O}}$
}

\author{
Z. E. Asong, S. RaZavi, H. S. Wheater, And J. S. Wong \\ Global Institute for Water Security and School of Environment and Sustainability, University of \\ Saskatchewan, Saskatoon, Saskatchewan, Canada
}

(Manuscript received 4 August 2016, in final form 15 January 2017)

\begin{abstract}
The Global Precipitation Measurement (GPM) mission offers new opportunities for modeling a range of physical/hydrological processes at higher resolutions, especially for remote river systems where the hydrometeorological monitoring network is sparse and weather radar is not readily available. In this study, the recently released Integrated Multisatellite Retrievals for GPM [version 03 (V03) IMERG Final Run] product with high spatiotemporal resolution of $0.1^{\circ}$ and $30 \mathrm{~min}$ is evaluated against ground-based reference measurements (at the 6-hourly, daily, and monthly time scales) over different terrestrial ecozones of southern Canada within a 23-month period from 12 March 2014 to 31 January 2016. While IMERG and ground-based observations show similar regional variations of mean daily precipitation, IMERG tends to overestimate higher monthly precipitation amounts over the Pacific Maritime ecozone. Results from using continuous as well as categorical skill metrics reveal that IMERG shows more satisfactory agreement at the daily and the 6-hourly time scales for the months of June-September, unlike November-March. In terms of precipitation extremes (defined by the 75th percentile threshold for reference data), apart from a tendency toward overdetection of heavy precipitation events, IMERG captured well the distribution of heavy precipitation amounts and observed wet/dry spell length distributions over most ecozones. However, low skill was found over large portions of the Montane Cordillera ecozone and a few stations in the Prairie ecozone. This early study highlights a potential applicability of V03 IMERG Final Run as a reliable source of precipitation estimates in diverse water resources and hydrometeorological applications for different regions in southern Canada.
\end{abstract}

\section{Introduction}

Precipitation $P$ is a climatic variable that provides critical information on the hydrological and energy cycles and is the key input to hydrological, agricultural, and water resource models. Hence, it is essential to derive high-quality estimates of the occurrence, intensity, and distribution of $P$ (Hou et al. 2014). Despite its significance, there is substantial uncertainty around $P$ estimates in many regions of the world. There is a pressing need for reliable estimates of $P$ on global to regional and subregional scales, stemming principally from the paucity of such information over large

Supplemental information related to this paper is available at the Journals Online website: http://dx.doi.org/10.1175/JHMD-16-0187.s1.

Corresponding authore-mail: Z. E. Asong, elvis.asong@usask.ca portions of Earth's surface (Huffman et al. 2007). Historically, estimation of spatially distributed $P$ fields has proved difficult and imprecise (Joyce et al. 2004; Newman et al. 2015). To date, there are three mainstream methods for obtaining $P$ datasets - gauge, radar, and satellites (New et al. 2001).

Gauges provide the most direct, representative, and reliable measurements of $P$ accumulation (Huffman et al. 2001). Nevertheless, in Canada (and many other countries), the low density of the gauge network and the inaccuracy of measurements, especially in northern Canada (north of $55^{\circ} \mathrm{N}$ ) and over the Rocky Mountains, where the gauges are typically $500-700 \mathrm{~km}$ apart, make the observation and quantification of $P$ challenging (Wang and Lin 2015). Particularly, as indicated by Goodison et al. (1998) and Peterson et al. (1998), $P$ gauges suffer from wind-induced turbulence around the gauge orifice that reduces catch efficiency, $P$ phase (liquid or solid) changes, evaporation/condensation, and blowing snow, sometimes 
accounting for sum measurement errors of as large as $50 \%-100 \%$ in winter. To reduce measurement errors, regular maintenance of gauges is often required, but the associated cost can be high, especially in remote, isolated regions with limited access roads such as along the Rocky Mountains and most of northern Canada. The $P$ estimates need to be quality controlled before use. Large correction factors can be required for snowfall measurements (e.g., Scaff et al. 2015).

Interpolation schemes that compute continuous spatial $P$ estimates often lead to errors (Tang et al. 2016), as gauge data are scattered sparsely over most continents, with few gauges located over islands and atolls and essentially none over oceans (Kidd and Huffman 2011). Also, inhomogeneities stem from the characteristics of $P$ : convective $P$ tends to be localized, high intensity, and of short duration, making its measurement more difficult, while stratiform $P$ is normally large scale and of longer duration, so that $P$ amounts recorded at neighboring sites usually have shared variance depending upon season and region (Asong et al. 2015, 2016a,b).

The advent and use of weather radar systems have addressed some of the shortcomings of gauge coverage, at least where radar exists (Ebert et al. 2007; Fortin et al. 2015). First, radar provides real-time, high-resolution measurement of $P$ over large regions rather than the point measurements provided by gauges, and second, it can observe the internal structure of storms (Yong et al. 2015). Still, radar suffers from various sources of error, including range-dependent systematic error (e.g., issues related to beam broadening with distance and visibility effects); mean-field systematic error (e.g., lack of electronic stability and miscalibration of the radar system); and random error, that is, fluctuations of the atmospheric conditions, including the variability in time and space of the vertical profile of reflectivity and issues associated with precipitation microphysics (Germann et al. 2006). Unfortunately, in Canada, the spatial coverage of weather radar is limited to the southern (south of $55^{\circ} \mathrm{N}$ ) part of the country (see, e.g., Fortin et al. 2015). Therefore, the most practical alternative to achieve comprehensive measurements of $P$ on a quasi-global basis is through the utilization of Earth observation satellites (Fritz and Wexler 1960; Hou et al. 2014).

In recent years, several satellite $P$ products have emerged that provide meteorological information at fine spatiotemporal resolutions and regular intervals. Presently, there are many quasi-global, high-resolution satellite $P$ products, including Precipitation Estimation from Remotely Sensed Information Using Artificial Neural Networks (PERSIANN; Sorooshian et al. 2000), Climate Prediction Center morphing technique (CMORPH; Joyce et al. 2004), Global Satellite Mapping of Precipitation
(GSMaP; Kubota et al. 2007), and Tropical Rainfall Measuring Mission (TRMM) Multisatellite Precipitation Analysis (TMPA; Huffman et al. 2007). These open access products have been applied both globally (e.g., Gottschalck et al. 2005; Hong et al. 2007; Liu 2015) and regionally (e.g., Bitew et al. 2012; Prakash et al. 2016). However, currently, the spatial coverage of the available satellite products is limited to latitudes $60^{\circ} \mathrm{S}-60^{\circ} \mathrm{N}$ (e.g., Sorooshian et al. 2000; Joyce et al. 2004; Huffman et al. 2014) and is therefore only of practical utilization in the southern part of Canada. Also, it has been reported that satellite-based $P$ estimates have large uncertainties, directly related to how the estimates are derived (Maggioni et al. 2016). These uncertainties may limit their direct use in practical applications (Gebremichael et al. 2003; Hossain and Huffman 2008).

Motivated by the success of the TRMM satellite, the Global Precipitation Measurement (GPM) Core $\mathrm{Ob}$ servatory was launched on 28 February 2014 as a joint project of the National Aeronautics and Space Administration (NASA) and the Japan Aerospace Exploration Agency (JAXA), marking a transition from the TRMM era to the GPM era (Hou et al. 2014). With a dualfrequency $P$ radar (DPR; Ku band at $13.6 \mathrm{GHz}$ and $\mathrm{Ka}$ band at $35.5 \mathrm{GHz}$ ) and a conical-scanning multichannel GPM Microwave Imager (GMI; frequencies span between 10 and $183 \mathrm{GHz}$ ), GPM sensors can detect light and solid $P$ more accurately than TRMM sensors. A high-resolution Integrated Multisatellite Retrievals for GPM (IMERG) dataset was released (in January 2015) that considers the regional and global error characteristics in TMPA estimates as a benchmark (Huffman et al. 2014). Although the GPM mission is opening up new opportunities for investigating the hydrologic processes, particularly in mountainous areas and ungauged river basins, the accuracies need to be evaluated against ground observations (e.g., Liu 2015; Prakash et al. 2016; Tang et al. 2016).

The main goal of this study is to perform a preliminary statistical evaluation of the post-real-time version 03 (V03) IMERG Final Run research quality product for specific terrestrial ecozones of southern Canada against ground-based observations. Specifically, we examine the quality of IMERG estimates for different $P$ characteristics (6-hourly, daily, and monthly totals and extremes) and regimes over these ecozones. Given that this is the first attempt to evaluate this product across Canada (to the best of our knowledge), we hope that it will provide useful insights into subsequent studies and applications of IMERG products as well as for hydrologic studies aiming to use IMERG estimates for watershed modeling, flood forecasting, and water resources management.

The rest of the paper is structured as follows. Section 2 provides a brief description of the study area and data 

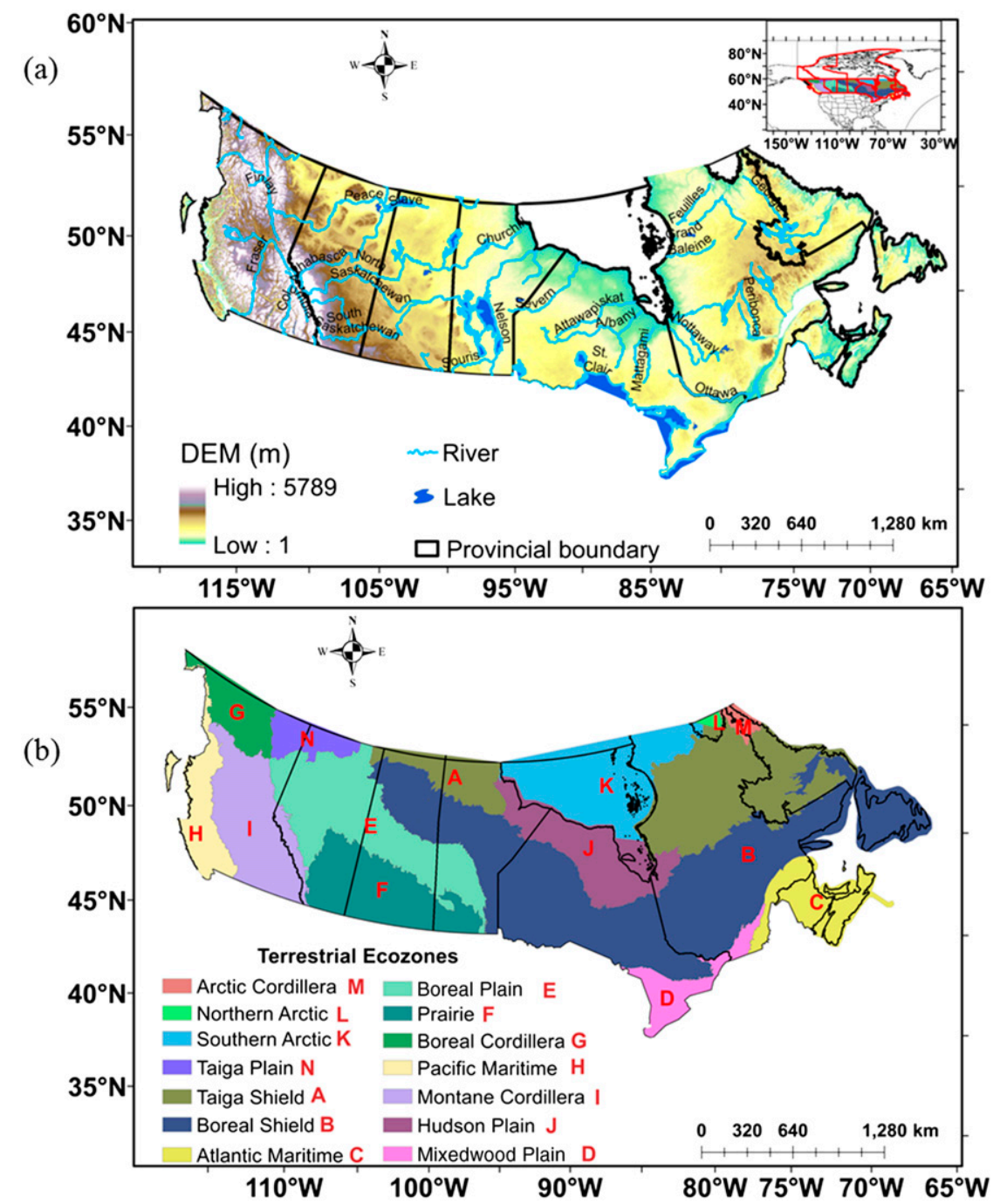

FIG. 1. Map of the study area showing (a) the topography and drainage as well as (b) terrestrial ecozones over southern Canada. The inset shows the location of the target region within Canada. The letters A-N represent each of the 14 ecozones considered in this study.

sources used. The metrics for comparing IMERG estimates against ground-based observations are described in section 3. Results of the evaluation as well as a discussion of the results within the general scientific context are provided in section 5 . The study is summarized and concluded in section 6 .

\section{Study area and data sources}

\section{a. Study area}

The study area comprises the Canadian landmass south of latitude $60^{\circ} \mathrm{N}$ (Fig. 1a). In this area, topography plays an important role in shaping disparate microclimates ranging from wet maritime on the coasts, to dry continental across the Prairies and Boreal Plain ecozones.
Snowfall is restricted to winter months (approximately October-April depending on region). The occurrence, intensity, and timing of seasonal $P$ greatly influence the functioning of ecosystems in various terrestrial ecozones (Fig. 1b) in this region (Hogg et al. 2000). Apart from topography, atmospheric circulation also controls precipitation patterns (Borchert 1950). Some of the major river basins in this region with headwaters in the Rocky Mountains include the Saskatchewan, McKenzie, and Fraser River basins. The study area is also home to the Great Lakes-St. Lawrence River system, which is one of the largest freshwater resources globally. Characterized by a highly variable hydroclimate and diminishing water resources, southern parts of this region contain the cities with high population density and support a vibrant agro-based 


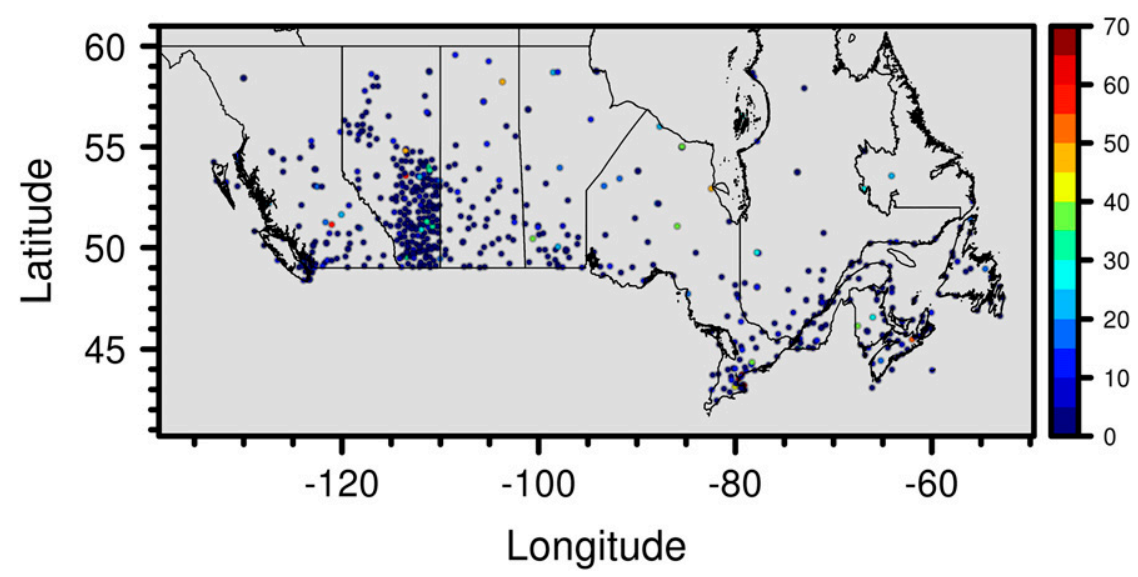

FIG. 2. Spatial distribution of the initial 732 ground-based precipitation gauges over the study area. Data screening for missing values (10\% threshold) led to 592 of these stations being selected and used for further analysis. The colors show the percentage of missing values found in the hourly dataset for the period from 12 Mar 2014 to 31 Jan 2016.

economy that was hard hit by the most severe and prolonged droughts of 1988 and 1999-2005, as well as severe floods of 2011, 2013, and 2014 (Wheater and Gober 2015).

\section{b. Data sources}

\section{1) SATELLITE PRECIPITATION PRODUCT}

In this study, the state-of-the-art IMERG mission with high space (time) resolution of $0.1^{\circ}(30 \mathrm{~min})$ is evaluated. IMERG utilizes the 2014 version of the Goddard profiling algorithm (GPROF) to compute precipitation estimates from all passive microwave (PMW) sensors on board the GPM Core Observatory and partner satellites. This is an improvement compared with TMPA (GPROF2010; Huffman et al. 2014). IMERG provides three products, including the nearreal-time Early ( $\sim 6 \mathrm{~h}$ after observation time) and Late $(\sim 18 \mathrm{~h}$ after observation time) Run products, and the post-real-time Final Run ( $\sim 4$ months after the observation month) product released in January 2015 (Huffman et al. 2015a). The IMERG Final Run combines the Global Precipitation Climatology Centre (GPCC; Schneider et al. 2014) level 3 full and monitoring precipitation gauge analyses (currently version 4) in the product. The GPCC data source is limited to the Global Telecommunications System (GTS) with about 75000 stations over the globe (Schneider et al. 2014). The V03 IMERG Final Run product, provided by the Day-1 IMERG algorithm, which is intended to intercalibrate, merge, and interpolate all microwave (MW) estimates of the GPM constellation, infrared (IR) estimates, and monthly $P$ gauge observational analysis at $0.1^{\circ} \times 0.1^{\circ}$ and half-hourly temporal resolutions, is used in the current study [see Huffman et al. (2014) for further details]. The analysis is restricted to the period from 12 March 2014 to 31 January 2016 based on IMERG data availability for southern Canada to October 2016, when the data were downloaded from the Precipitation Measurement Mission (PMM) website (http://pmm. nasa.gov/data-access/downloads/gpm).

\section{2) GROUND-BASED OBSERVATIONS}

\section{(i) Gauge precipitation observation}

The in situ $P$ data used in this study are hourly $P$ totals from the weather station networks available in the Canadian Meteorological Centre (CMC) database at 732 stations located across southern Canada (Fig. 2). The concentration of stations south of latitude $55^{\circ} \mathrm{N}$ is noticeable. This station network is maintained by Environment and Climate Change Canada (ECCC) (http:// climate.weather.gc.ca/historical_data/search_historic_ data_e.html) and data are freely available upon request. A strict quality control procedure has been applied by ECCC to check and correct erroneous values and issues of wind undercatch (e.g., Fortin et al. 2008). The data were extracted for the period from 12 March 2014 to 31 January 2016. Out of 732 stations, 140 of these stations were found to have more than $10 \%$ of missing data in a particular month and were discarded, while 592 were retained for further consideration. This dataset is hereafter referred to as EC-S (S for station). An inventory of these sites (see Table S1) is included in the supplemental material. To ensure a valid comparison, a check was made to ensure that $<20 \%$ of gauges used in this study were utilized by GPCC (https://kunden.dwd. de/GPCC/Visualizer) for intercalibrating GPM satellite 
estimates during the study period. Therefore, the evaluation and comparison in this study are based on more than $80 \%$ independent gauge stations (not used for IMERG calibration). IMERG algorithm uses the GPCC monthly gauge data to create the V03 IMERG Final Run product, but the comparison in our study was conducted mostly at subdaily and daily time scales.

\section{(ii) Gridded CaPA}

Apart from using in situ weather station measurements as the benchmark for comparing IMERG estimates, we also used 6-hourly gridded $P$ data from 12 March 2014 to 31 January 2016 with a horizontal resolution of $10 \mathrm{~km}$ provided free of charge upon request by the Meteorological Service of Canada (MSC; https://weather.gc.ca/grib/grib2_RDPA_ps10km_e.html). This data system called the Canadian Precipitation Analysis (CaPA), which provides nationwide quantitative precipitation estimates (QPEs), has been created to address the generally low density of weather stations in Canada (particularly in the northern portions of the country) and the fact that in mountainous regions, weather stations are often located in valleys and thus are not able to accurately capture the orographic effects on precipitation. CaPA is based on an optimal interpolation procedure (Daley 1991) that combines different sources of information (surface observations/ gauges, radar, and numerical weather prediction model output) on $P$ amounts (Fortin and Roy 2011; Lespinas et al. 2015). CaPA has constantly been improved since 2003 and became operational in April 2011 (Mahfouf et al. 2007). The flexibility of the CaPA system allows for easy inclusion of new sources of observations (e.g., satellite-based estimates) if such become available [see Fortin et al. (2015) for more on CaPA].

\section{Methodology}

This section describes the procedure employed to quantitatively verify the satellite-gauge product (IMERG) against the two ground-based benchmark observations discussed in section $2 \mathrm{~b}$ (ii). As IMERG has a different horizontal resolution $(\sim 11 \mathrm{~km})$ from that of CaPA $(\sim 10 \mathrm{~km}), \mathrm{CaPA}$ was regridded onto IMERG grid via bilinear interpolation for direct comparison. The satellite-gauge product (IMERG) was compared with the gauge (EC-S) $P$ and CaPA data at the 6-hourly, daily, and monthly time scales (daily $P$ was summed to monthly) for different terrestrial ecozones over the study region (Fig. 1b). However, it is important to note that sample sizes (number of sites) differ between ecozones; therefore, certain small sample cases may create uncertainty when comparing results across ecozones.
IMERG was compared against CaPA at two different spatial scales: 1) EC-S point scale and 2) CaPA grid scale. Using CaPA at both point and grid scale to evaluate IMERG is motivated by the fact that the network of synoptic stations (EC-S) was also used for deriving CaPA QPEs (Fortin and Roy 2011; Fortin et al. 2015). Thus, the agreement between CaPA and IMERG at both point and grid scale will provide further insights about the potential for assimilating IMERG QPEs within CaPA (V. Fortin 2016, personal communication).

It is impossible to get perfect spatial matching between point measurements (gauge accumulation over several minutes to several hours), and the areal value (snapshot) estimated by the satellite (Hong et al. 2007). Therefore, fundamental challenges exist when comparing point measurements and satellite estimates: retrieval errors of satellite algorithms, sampling errors originating from various sampling schemes, and errors related to gauge instrumentation (Bowman 2005). However, the aim of this study was not to quantify how well IMERG reproduces individual $P$ events, but to assess the overall performance of IMERG from 12 March 2014 to 31 January 2016 across different ecozones. Apart from assessing IMERG at grid scale, the performance evaluation was also carried out at the locations of the 592 gauges retained for further consideration. For this, a matched $P$ series of gridded IMERG and CaPA products for each gauge was obtained by combining the surrounding four grid cells via bilinear interpolation (note that this procedure has the effect of smoothing the area averages). Integrating the values at the nearest four grids instead of the single grid where the $P$ gauge falls can reduce errors caused by wind and other spatial sampling issues (e.g., Bowman 2005). Since the EC-S gauge-based dataset (http://climate. weather.gc.ca/prods_servs/documentation_index_e.html) and CaPA accumulations are provided at 0000, 0600, 1200, and 1800 UTC, daily $P$ was computed from gauges, CaPA, and IMERG data ending at 1800 UTC. To evaluate the ability of IMERG to detect $P$ occurrence, and amounts when wet, the following metrics, which can be classified into continuous and categorical verification statistics (Jolliffe and Stephenson 2003), were used. Although this analysis is performed at three time scales ( 6 hourly, daily, and monthly), the following metrics are not applied to data at all time scales. Where appropriate, the time scale and metric used is clearly stated.

\section{a. Continuous verification statistics}

As the most commonly used metrics for validation of satellite products, continuous $(\mathrm{CON})$ verification statistics 
TABLE 1. Two-by-two contingency table showing counts. The $n_{i j}$ values represent the counts in each estimated $i$ and observed $j$ category. The subscript dot $(\bullet)$ indicates sums across categories. Hits (i.e., $n_{11}$ ) are events detected by the satellite to occur and that did occur. False alarms (i.e., $n_{10}$ ) are events detected by the satellite to occur but that did not occur. Misses (i.e., $n_{01}$ ) are events detected by the satellite not to occur but that did occur. Correct negatives (i.e., $n_{00}$ ) are events detected by the satellite not to occur and that did not occur.

\begin{tabular}{|c|c|c|c|}
\hline \multirow[b]{2}{*}{ Estimated } & \multicolumn{2}{|c|}{ Observed } & \multirow[b]{2}{*}{ Total } \\
\hline & $\begin{array}{l}Y=1 \\
(\text { yes })\end{array}$ & $\begin{array}{c}Y=0 \\
(\text { no) }\end{array}$ & \\
\hline $\begin{array}{l}S=1 \\
\quad(\text { yes })\end{array}$ & $n_{11}$ & $n_{10}$ & $n_{1 \bullet}=n_{11}+n_{10}$ \\
\hline $\begin{array}{l}S=0 \\
\quad \text { (no) }\end{array}$ & $n_{01}$ & $n_{00}$ & $n_{0 \bullet}=n_{01}+n_{00}$ \\
\hline Total & $n_{\bullet 1}=n_{11}+n_{01}$ & $n_{\bullet 0}=n_{10}+n_{00}$ & $T=n_{11}+n_{10}+n_{01}+n_{00}$ \\
\hline
\end{tabular}

aim to measure the accuracy of a continuous variable such as the $P$ amount or intensity above a threshold. The metrics mean error (ME), root-mean-square error (RMSE), and Pearson correlation coefficient (Cor) were utilized (Jolliffe and Stephenson 2003). ME measures the average difference between the estimated and observed values:

$$
\mathrm{ME}=\frac{1}{N} \sum_{i=1}^{N}\left(S_{i}-Y_{i}\right)
$$

RMSE is some average of error magnitudes that gives greater weight to larger errors, but does not indicate the direction of the deviations:

$$
\mathrm{RMSE}=\sqrt{\frac{1}{N} \sum_{i=1}^{N}\left(S_{i}-Y_{i}\right)^{2}} .
$$

Cor measures the degree of linear association or phase error between the estimated and observed values of $P$. It does not take into account absolute or conditional biases (e.g., it is possible for an estimate with large errors to still have a good correlation coefficient with the observations) and therefore must be used along with other measures when verifying satellite estimates:

$$
\text { Cor }=\frac{\sum_{i=1}^{N}\left(S_{i}-\bar{S}\right)\left(Y_{i}-\bar{Y}\right)}{\sqrt{\sum_{i=1}^{N}\left(S_{i}-\bar{S}\right)^{2}} \sqrt{\sum_{i=1}^{N}\left(Y_{i}-\bar{Y}\right)^{2}}} .
$$

In the equations above, $S_{i}$ indicates the estimated value at point $i ; Y_{i}$ indicates the observed value at point $i ; \bar{S}$ and $\bar{Y}$ are the corresponding mean values, respectively; and $N$ is the number of samples.

\section{b. Categorical verification statistics}

Categorical (CAT) verification statistics measure the agreement between the estimated and observed occurrence of $P$ events. The capability of IMERG to distinguish dichotomous (yes/no) $P$ events (Table 1) was assessed by using the following set of contingency table statistics (Table 2; Jolliffe and Stephenson 2003; Ferro and Stephenson 2011): frequency bias (FBIAS), probability of detection (POD), false alarm ratio (FAR), equitable threat score (ETS), extreme dependency score (EDS), symmetric extreme dependency score (SEDS), and symmetric extremal dependence index (SEDI). Additionally, we investigated the ability of IMERG to reproduce persistence that is often found in $P$ sequences. For this purpose, dry and wet spell length characteristics were analyzed. Let $P_{i j}$ be the daily $P$ amount on day $i$ in period $j$. Then the maximum length of wet spell [consecutive wet days (CWD)] is a count of the largest number of consecutive days where $P_{i j} \geq n$th percentile threshold while the maximum length of dry spell [consecutive dry days (CDD)] is a count of the largest number of consecutive days where $P_{i j}<n$th percentile threshold.

As stated in section 1 , the objective of this study was to examine the performance of IMERG in comparison with the observed $P$ totals and extremes. For $P$ totals, $0.01(0.5) \mathrm{mm}$ was used to define a wet threshold at the 6-hourly (daily) time scale (e.g., Asong et al. 2016a,b). Subsequently, ME, RMSE, and Cor were applied to conditional $P$ amounts while CAT metrics (POD, FAR, and ETS) were applied to the binary $P$ series of rain/no rain events. To characterize extremes, an additional threshold corresponding to the 75 th percentile (each for the 6-hourly and the daily time scale) of observed $P$ over each ecozone was defined. Subsequently, extremal dependency metrics (EDS, SEDS, and SEDI) for verifying rare events (Ferro and Stephenson 2011) were applied to the binary $P$ series. As EDS is independent of bias, it was presented alongside the FBIAS. Finally, the spell length statistic (CWD/CDD) was computed from the binary $P$ series defined by the ecozone-dependent 75 th percentile threshold.

\section{Results and discussion}

In this section, results of the performance of IMERG against the two ground-based benchmark observations are presented. We evaluate the effectiveness of IMERG to detect mean and extreme $P$ over southern Canada at the 6-hourly, daily, and monthly time scales. Specifically, this study sought to investigate how well IMERG reproduced 1) the 
TABLE 2. List of the categorical (binary) scores used in this study. In the formulas, $H=$ POD and $F=$ FAR.

\begin{tabular}{|c|c|c|c|}
\hline Score & Formula & Perfect value (range) & Description \\
\hline FBIAS & $\frac{n_{11}+n_{10}}{n_{11}+n_{01}}$ & $1(0 \sim \infty)$ & $\begin{array}{l}\text { Ratio of total number of estimated } \\
\text { to total number of observed events } \\
\text { FBIAS }>1 \text { : overestimation; } \\
\text { FBIAS }<1 \text { : underestimation }\end{array}$ \\
\hline POD & $\frac{n_{11}}{n_{11}+n_{01}}$ & $1(0 \sim 1)$ & $\begin{array}{l}\text { Fraction of observed events that were } \\
\text { correctly detected by satellite }\end{array}$ \\
\hline FAR & $\frac{n_{10}}{n_{10}+n_{11}}$ & $0(0 \sim 1)$ & $\begin{array}{l}\text { Fraction of detected events that were } \\
\text { not observed }\end{array}$ \\
\hline ETS & $\begin{aligned} & \frac{n_{11}-C_{1}}{n_{11}+n_{10}+n_{01}-C_{1}}, \\
C= & \frac{\left(n_{11}+n_{10}\right)\left(n_{11}+n_{01}\right)}{T}, \text { and } \\
T= & n_{11}+n_{10}+n_{01}+n_{00} \\
& 2 \ln \left(\frac{n_{11}+n_{01}}{T}\right)\end{aligned}$ & $1(-1 / 3 \sim 1)$ & $\begin{array}{l}\text { Fraction of observed events that were } \\
\text { correctly detected with adjusted } \\
\text { hits due to random chance }\end{array}$ \\
\hline EDS & $\frac{1}{\ln \left(\frac{n_{11}}{T}\right)}-1$ & $1(-1 \sim 1)$ & $\begin{array}{l}\text { Measures the association between } \\
\text { observed and detected rare events }\end{array}$ \\
\hline \multirow{2}{*}{ SEDS } & $2 \ln \left[\frac{\left(n_{11}+n_{01}\right)\left(n_{11}+n_{10}\right)}{T^{2}}\right]$ & \multirow{2}{*}{$1(-\infty \sim 1)$} & \multirow[b]{2}{*}{$\begin{array}{l}\text { Measures the association between } \\
\text { observed and detected rare events }\end{array}$} \\
\hline & $\ln \left(\frac{n_{11}}{T}\right)$ & & \\
\hline \multirow[t]{2}{*}{ SEDI } & $\begin{array}{c}\frac{\ln F-\ln H+\ln (1-H)-\ln (1-F)}{\ln F+\ln H+\ln (1-H)+\ln (1-F)} \\
H=\frac{n_{11}}{n_{11}+n_{01}}, \text { and }\end{array}$ & $1(-\infty \sim 1)$ & \multirow[t]{2}{*}{$\begin{array}{l}\text { Measures the association between } \\
\text { observed and detected rare events }\end{array}$} \\
\hline & $F=\frac{n_{10}}{n_{00}+n_{10}}$ & & \\
\hline
\end{tabular}

pattern of wet/dry sequences ( $P$ occurrence) and 2$)$ the conditional distributions of $P$ amounts at different temporal scales. The grid-scale assessment of IMERG against $\mathrm{CaPA}$ is included in the accompanying supplemental material.

\section{a. Spatial patterns of IMERG and reference datasets}

A simple visual comparison of satellite estimates and observations ("eyeball" verification; Ebert and McBride 2000) is one of the most effective verification methods. Figure 3 shows the spatial distribution of the 23-month mean daily $P$ for IMERG, CaPA, and EC-S over the study area. It is noticeable that IMERG can successfully capture the spatial structure of $P$ over the study area. Particularly, the pattern and magnitude in regions of heavy $P$, such as along the western coast (e.g., Pacific Maritime, where the orographic effect plays an important role in bringing heavy $P$ on the windward side and the nearby ocean), and most of the eastern coast (e.g., Atlantic Maritime and parts of Boreal and Taiga Shields) is well reproduced. Apart from some regions in the Montane and Boreal Cordillera where, compared to CaPA, IMERG shows an underestimation of mean
$P(\sim 1.5 \mathrm{~mm})$, the structure over the Alberta plateau and most of the continental interior with lesser $P$ amounts is well captured.

\section{b. Evaluation according to terrestrial ecozones}

\section{1) VERIFICATION OF PRECIPITATION TOTALS}

In this subsection, results of both CON and CAT verification metrics applied to the thresholded data are presented. We first examined how well IMERG reproduced the distributional properties of observed ground-based $P$ when wet. Figure 4 depicts quantilequantile $(\mathrm{Q}-\mathrm{Q})$ plots of monthly $P$ for all sites within an ecozone (cf. Fig. 1b). Each dot represents monthly $P$ from one site. IMERG agreed well with CaPA and EC-S over ecozones A, B, C, D, E, G, and J, but with a tendency to underestimate larger $(>150 \mathrm{~mm})$ EC-S $P$ amounts in these ecozones. Overall, the performance of IMERG is relatively better on the east coast and most of the interior plains but less so over the Rocky Mountains (ecozone I, underestimation) and Pacific Maritime (ecozone $\mathrm{H}$ ), where most of the precipitation formation is governed by maritime and orographic effects. 


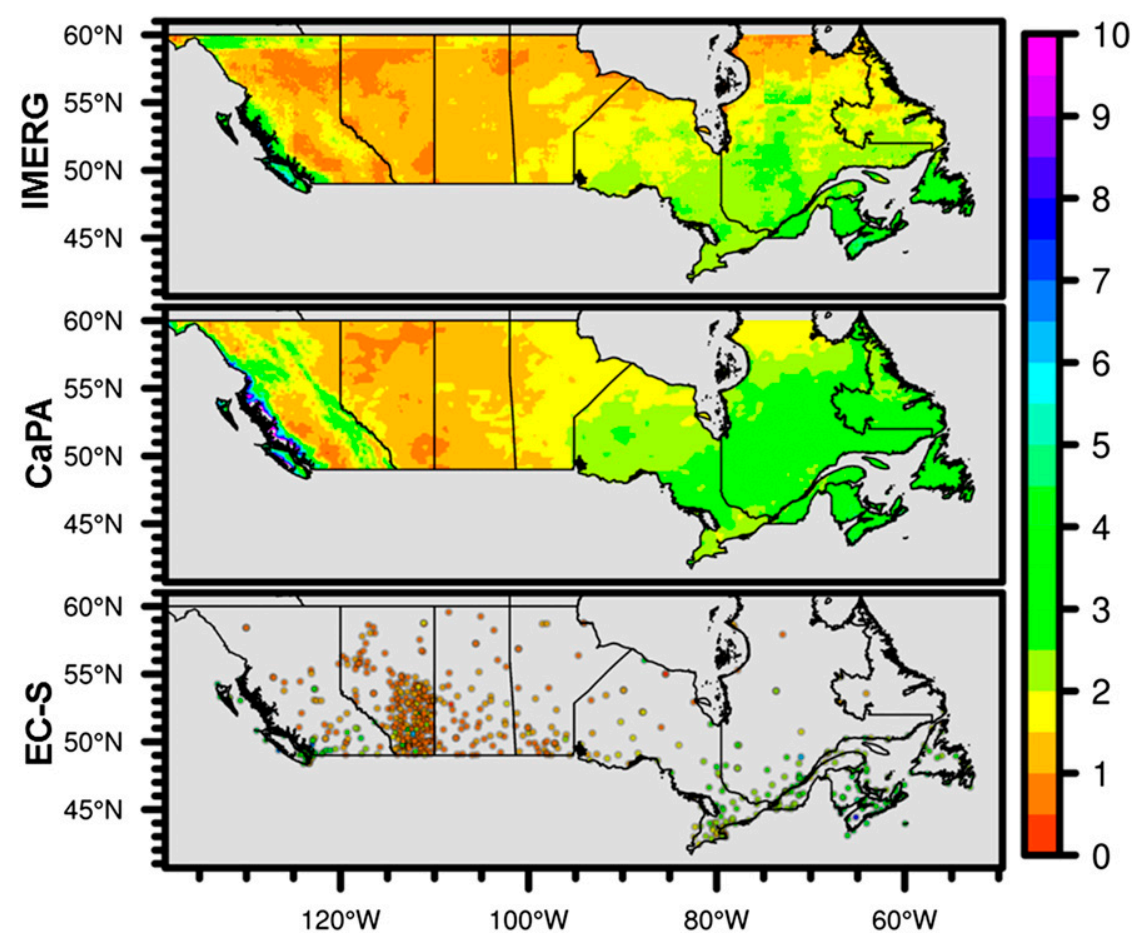

FIG. 3. Spatial structure of 23-month mean daily precipitation $\left(\mathrm{mm} \mathrm{day}^{-1}\right)$ for IMERG, CaPA, and EC-S over the study area.

Monthly $P$ amounts are overestimated in ecozone $\mathrm{H}$ when compared to both CaPA and EC-S datasets.

Spatial distributions of Cor, ME, and RMSE for IMERG 6-hourly and daily $P$ over southern Canada are shown in Fig. 5. Overall, IMERG shows stronger linear association with EC-S and CaPA, and more so at the daily than the 6-hourly time scale. In terms of regional performance, more correspondence is found over the Prairie (F), and much of the east and west coast where Cor ranges between 0.5 and 0.9 at the daily scale. Based on Cor, the performance of IMERG is weaker $($ Cor $<0.5)$ over much of the Boreal and Montane Cordillera but shows more association with CaPA compared to EC-S. However, IMERG exhibits larger biases (ME) of daily $P$ over the coastal maritime (ecozones $\mathrm{C}$ and $\mathrm{H}$ ) areas (ME $\sim 1.5-5 \mathrm{~mm}$ ) compared to ecozones over the continental interior characterized by an alternate distribution of ME values ranging between -1.2 and $1.2 \mathrm{~mm}$. Similar results were found for grid-scale comparisons (Fig. S1 in the supplemental material).

The performance of IMERG by month of the year is shown in Fig. 6 for daily $P$. A specific comparison for each ecozone is applied to further understand the accuracy of the IMERG product over different regions of southern Canada. The distributions of CAT metrics within each ecozone are discussed here. It is noticeable that the quality of IMERG is lower during the winter months of December-February, as judged from the low ETS and POD, and the corresponding high FAR values in all ecozones except $\mathrm{H}(\mathrm{H}$ is the Pacific Maritime region with less snowfall in winter). However, the performance is higher in the months of June-September over all ecozones where higher median ETS $(\sim 0.25-0.5)$ and POD $(\sim 0.3-0.75)$ and relatively lower FAR $(0-0.35)$ values can be found. It is important to note that the distributions shown here are for all sites in each ecozone. Again, as in the case of CON metrics, IMERG better reproduces the intraecozone distributions of daily $P$ occurrence when evaluated against EC-S (blue) than against CaPA (red).

The capability of IMERG to reproduce the observed binary distribution of $P$ totals was further assessed for each site across the study area. Figure 7 illustrates the spatial pattern of contingency table statistics between EC-S, CaPA, and IMERG at the 6-hourly and the daily time scales. At the 6-hourly time scale, IMERG was able to reproduce reasonably the fraction of observed events adjusted for hits due to random chance (ETS). However, evaluation against CaPA (ETS $\sim 0.0-0.4$ ) shows improved performance unlike against EC-S (ETS $\sim 0.0-0.2$ ) at both time scales. Based on ETS, the performance of IMERG degrades over the Montane Cordillera and much of the interior plains when compared against EC-S. Although with higher ETS values, similar spatial 


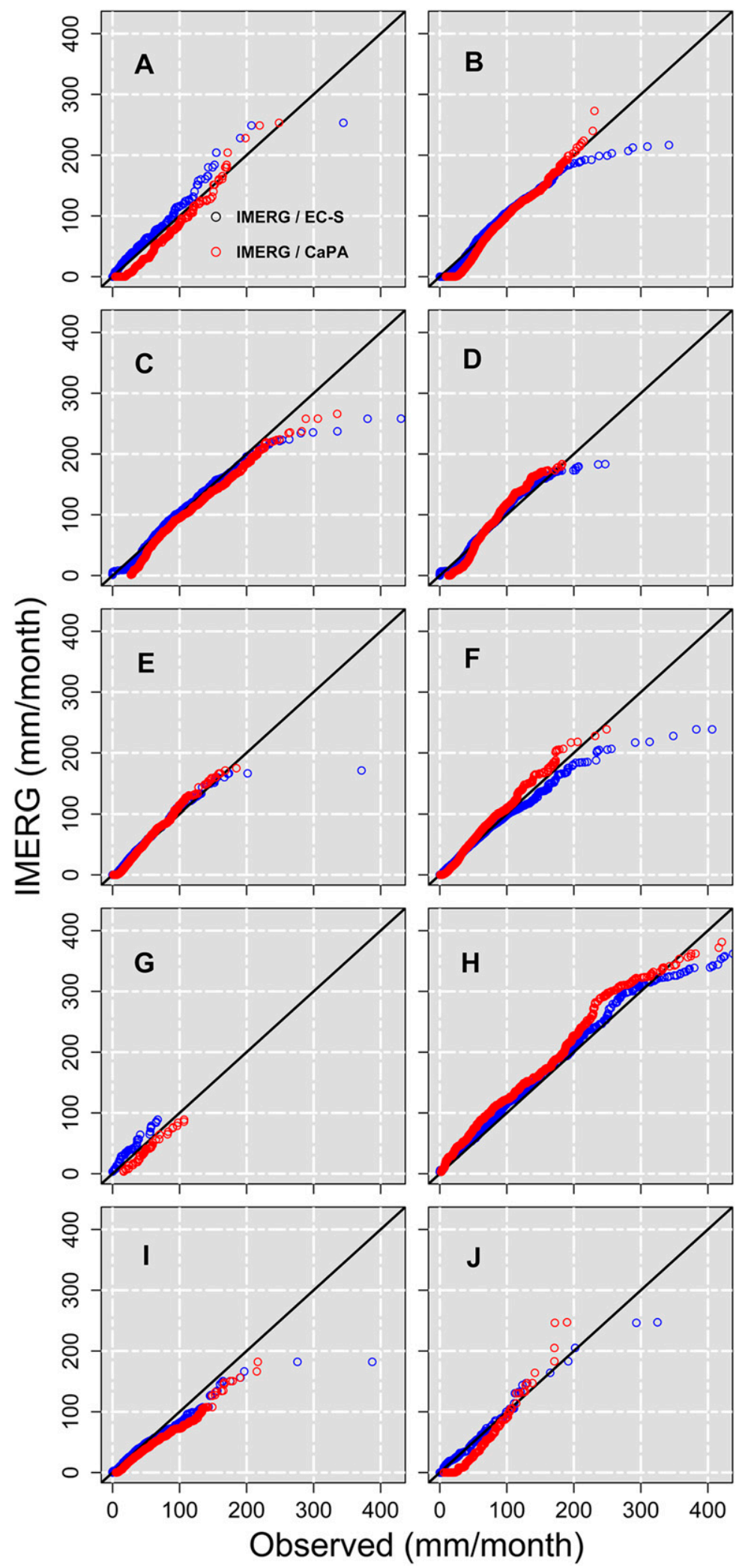

FIG. 4. The Q-Q plots of observed and satellite-derived (IMERG) precipitation $\left(\mathrm{mm} \mathrm{month}{ }^{-1}\right)$ pooled over the number of sites in each ecozone. The red and blue dots indicate the observed CaPA and EC-S precipitation amounts, respectively. 


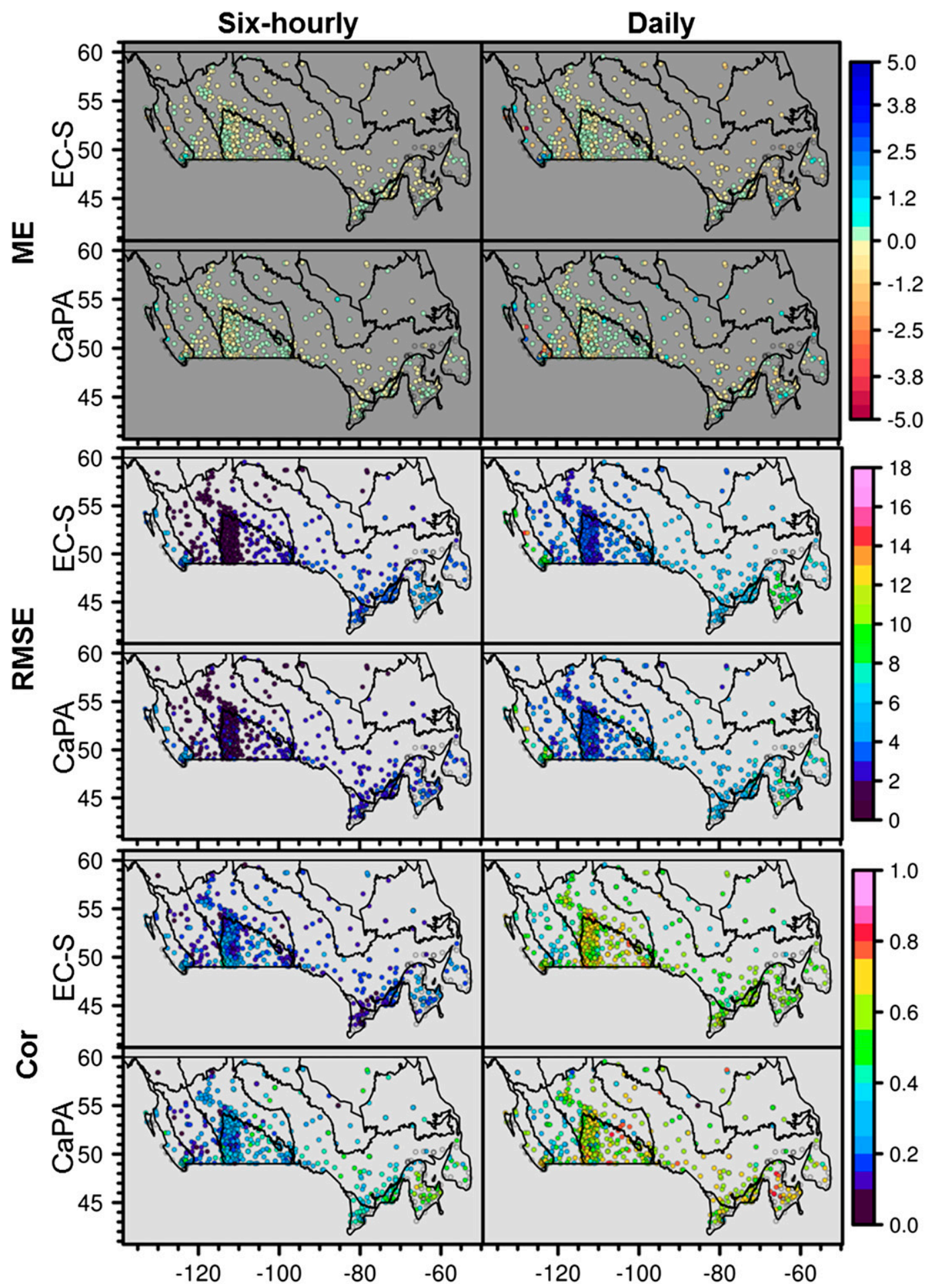

FIG. 5. The spatial pattern of continuous verification statistics between observed ground-based products (EC-S and CaPA) and the satellite-derived product (IMERG) from 12 Mar 2014 to 31 Jan 2016. Red means underestimation and blue means overestimation in the case of ME. Note that every circle represents a gauge station, and open circles represent discarded sites with $10 \%$ of missing data in a particular month. 


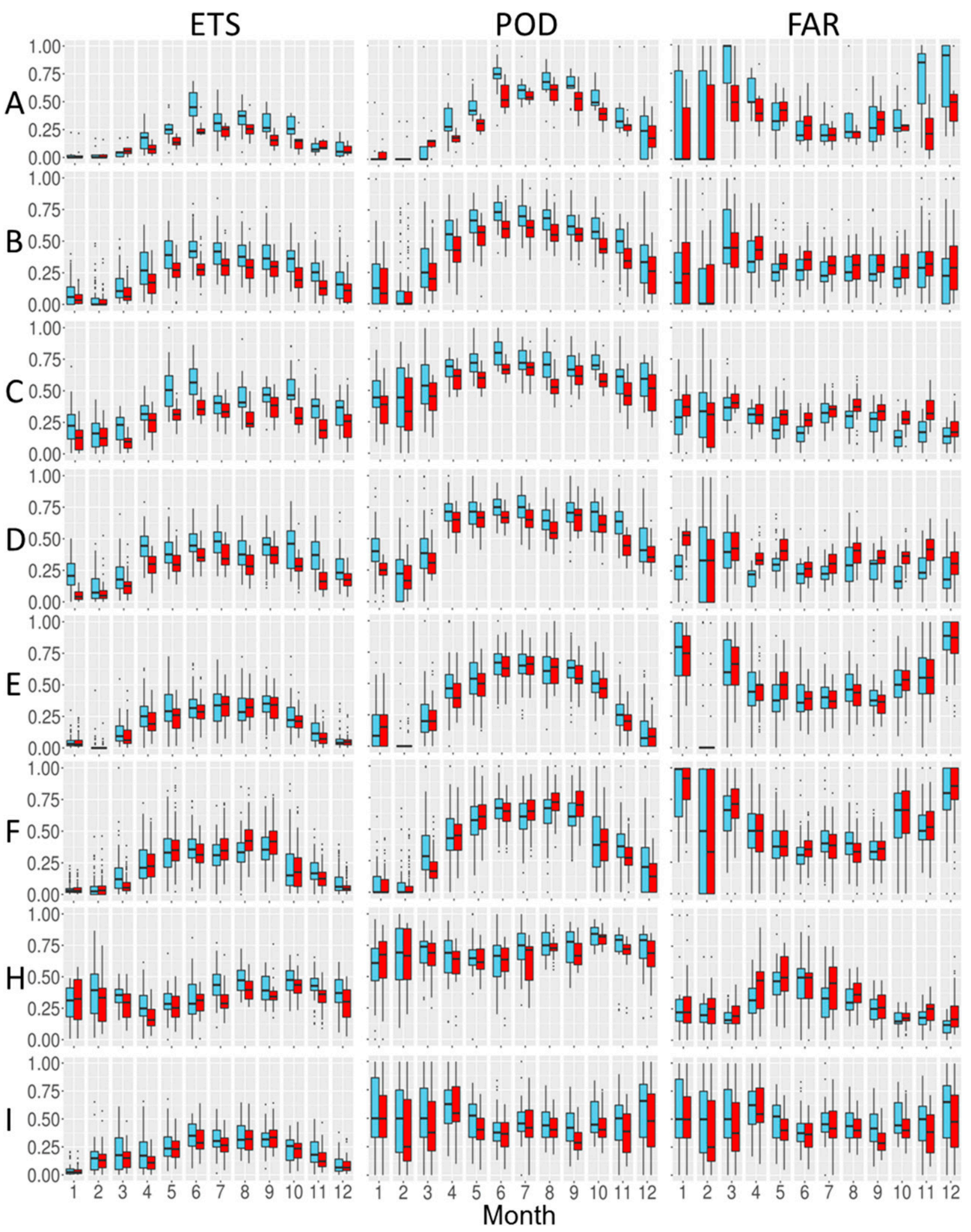

FIG. 6. Box plots showing the performance of IMERG for each month of the year at daily time scale using a threshold of $0.5 \mathrm{~mm}^{-1 a y}{ }^{-1}$. The red and blue boxes indicate the observed CaPA and EC-S reference datasets, respectively, in each ecozone (A, B, C, D, E, F, H, and I). In each box plot, the box corresponds to the interquartile range, the line in the middle of the box corresponds to the median value, and the whiskers correspond to either the max or min value of the metrics (ETS, PDO, and FAR). 


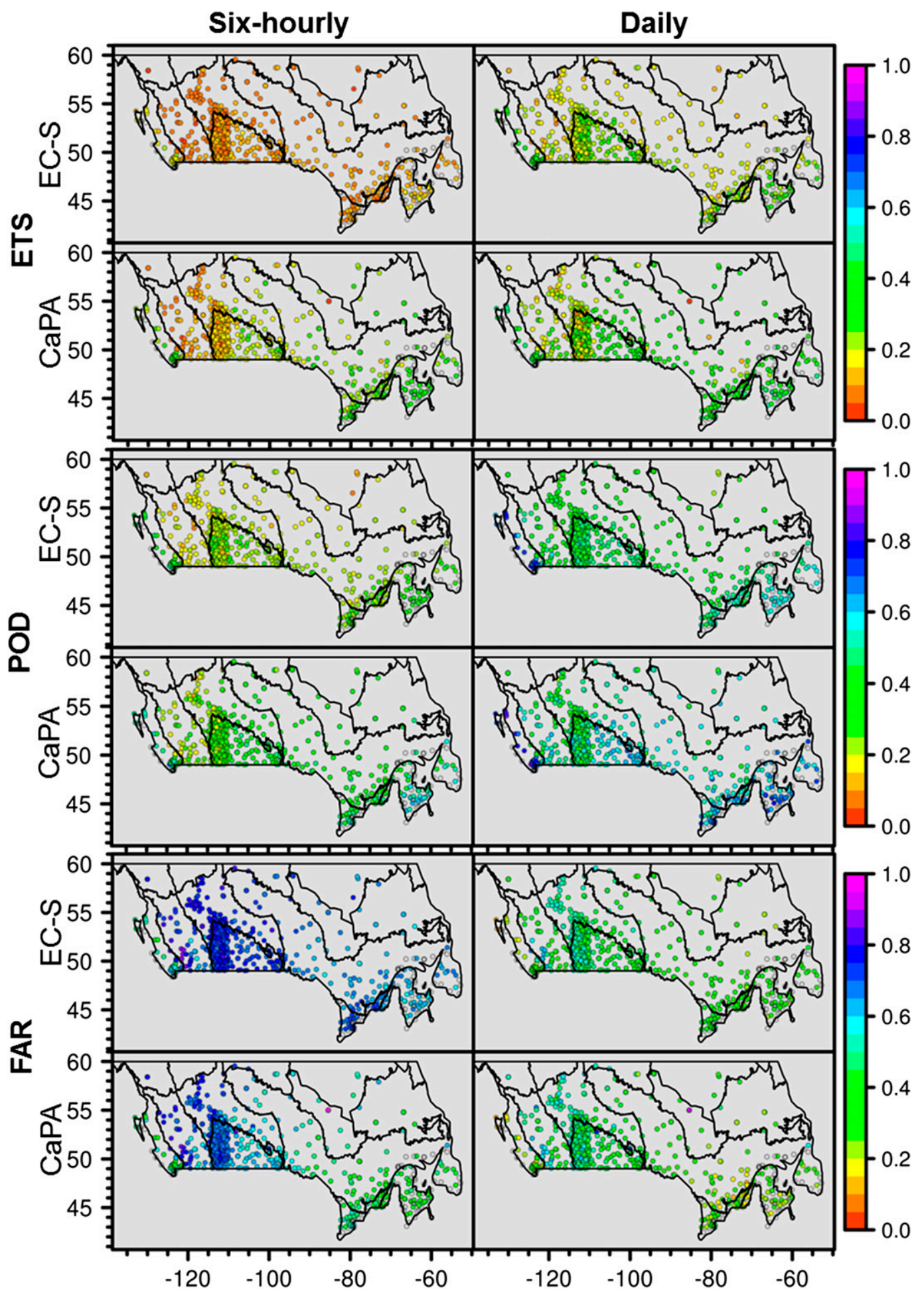

FIG. 7. The spatial pattern of contingency table statistics (ETS, POD, and FAR) between observed ground-based products (EC-S and CaPA) and the satellite-derived product (IMERG) from 12 Mar 2014 to 31 Jan 2016. Note that every circle represents a gauge station. 


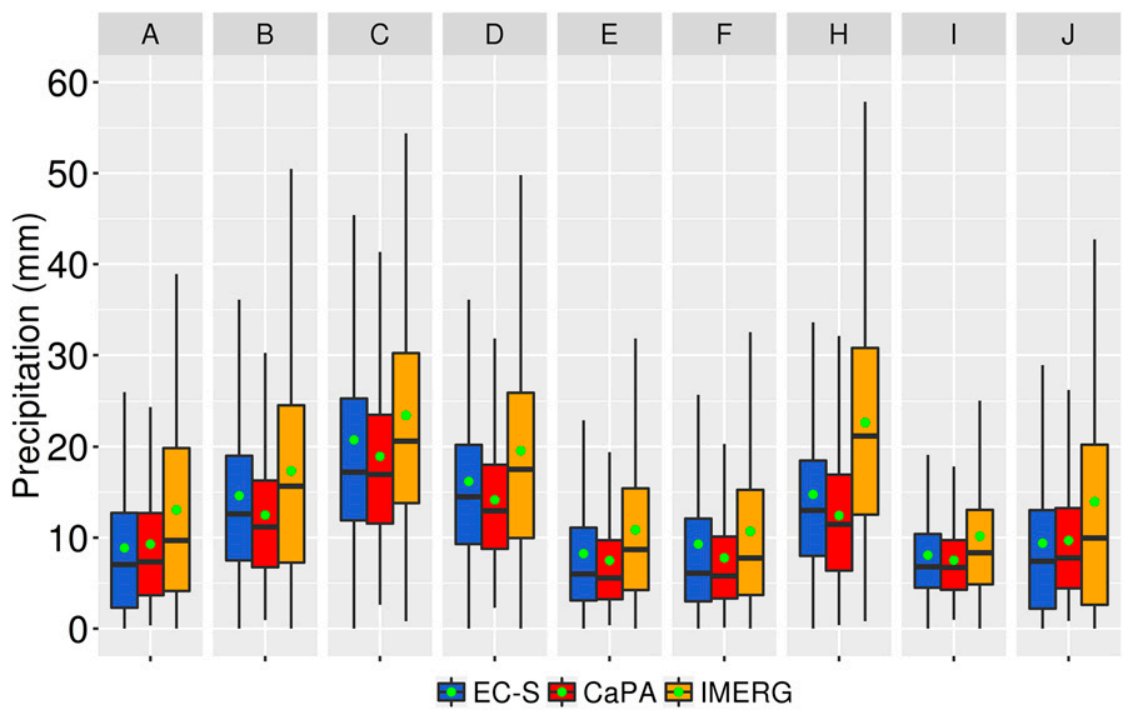

FIG. 8. Intraecozone distribution of 6-hourly maxima (single day) of accumulated precipitation totals for IMERG, CaPA, and EC-S from 12 Mar 2014 to 31 Jan 2016. The box plots show a distribution of the maxima pooled from all sites in each ecozone. The green dot is the mean value. Remaining convention the same as in Fig. 6.

patterns are found at the daily scale where higher ETS values can be found (EC-S: ETS $\sim 0.0-0.5$; CaPA: ETS $\sim 0.0-0.7)$. Noticeably, IMERG shows reduced quality over the Hudson Plain when compared against EC-S (a grid-scale comparison can be found in Fig. S2 in the supplemental material). In terms of capturing correctly the fraction of observed "yes" events (POD), IMERG performs better at the daily than the 6-hourly time scale. In particular, higher POD $(\sim 0.8)$ and lower FAR $(\sim 0.2)$ can be found along the east and west coast in the case of CaPA at the daily scale compared to EC-S (POD 0.6; FAR 0.3). Regionally, IMERG detects weakly the $P$ events over the Prairie, Rocky Mountains, and the transition zones between the Boreal Shield and the Mixedwood Plain as judged by the high FAR values at the 6-hourly scale in the case of EC-S. Overall, the performance of IMERG is better at the daily than the 6-hourly scale (see also Fig. S2 in the supplemental material) as expected.

\section{2) VERIFICATION OF PRECIPITATION EXTREMES}

Furthermore, this study assessed the quality of IMERG estimates in terms of detecting heavy $P$ events over southern Canada. We first evaluate the distributional properties of heavy $P$ in terms of maxima of accumulated conditional $P$ amounts as well as the spell length statistic and contingency table extremal dependency indices (see section $3 \mathrm{~b}$ ). Figure 8 shows the intraecozone distribution of 23-month, 6-hourly maxima (one value per site) of accumulated $P$ amounts for
IMERG, CaPA, and EC-S during the study period. The box plots show the distribution of the maxima pooled from all sites in each ecozone. Overall, IMERG was able to reproduce well the distribution of maximum accumulated $P$ when compared to EC-S and CaPA. Compared to CaPA, IMERG indicates a tendency to overestimate heavy $P$ amounts unlike when evaluated against EC-S. Although with higher variability (as indicated by the interquartile range) and a tendency toward overestimation, IMERG captures well the distribution of heavy $P$ amounts over most ecozones. Regionally, better performance is found over the continental semiarid [Boreal Plain (E) and Prairie (F)] ecozones compared to relatively humid ecozones [Atlantic Maritime (C) and Pacific Maritime (H)], where median-heavy $P$ amounts are systematically overestimated. For example, in ecozone $\mathrm{H}$, the median 6-hourly heavy $P$ amounts are 21,13 , and $11 \mathrm{~mm}$ for IMERG, EC-S, and CaPA, respectively.

The IMERG product was also evaluated in terms of reproducing the observed wet/dry spell length distributions. Such information is crucial for various water management and agricultural development efforts in this drought-prone region of Canada. The maximum consecutive wet spell length (CWD) based on daily $P$ is shown in Fig. 9. First, IMERG was found to reproduce the CWD very well when assessed against EC-S, unlike against CaPA, where the performance reduces appreciably over these ecozones: Taiga Shield (A), Pacific Maritime (H), and Hudson Plain (J) (the CWD in CaPA 


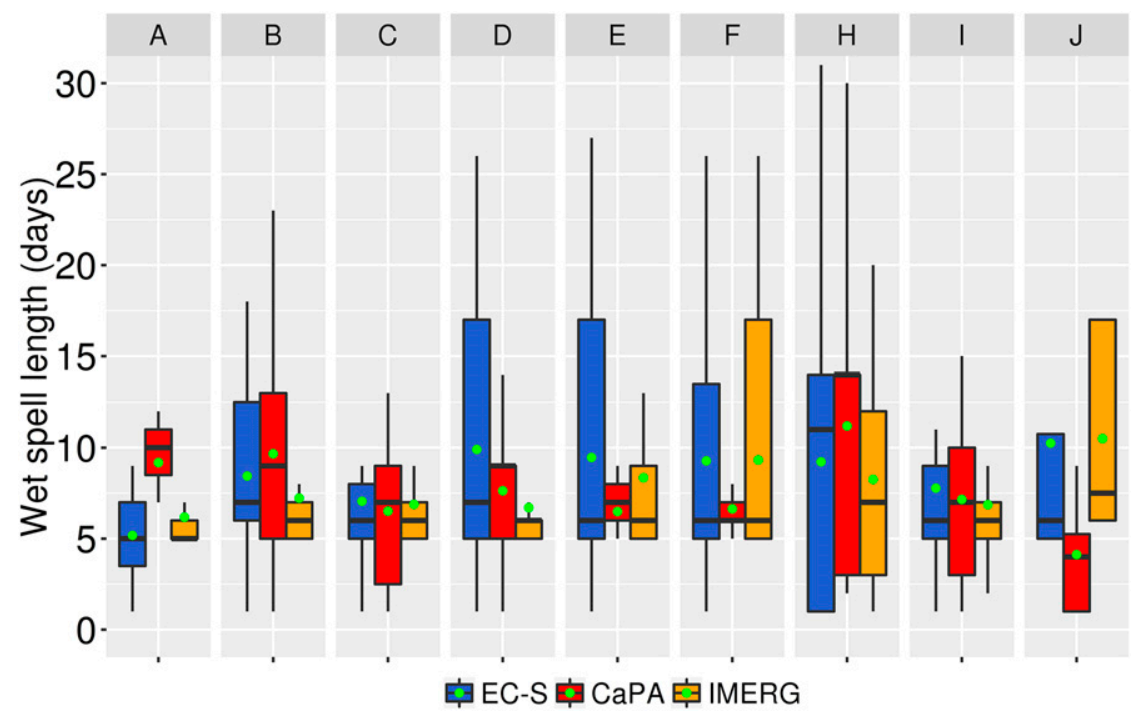

FIG. 9. Performance of IMERG in terms of reproducing the intraecozone distribution of observed wet spell length (CWD) characteristics using the 75th percentile threshold at daily time scale. Remaining convention the same as in Fig. 6.

are underestimated relative to EC-S). CaPA was also shown in Fig. 5 to have low biases (ME and RMSE). It is not surprising that the mean longest run of very wet days ( 12) from 12 March 2014 to 31 January 2016, which is well detected by IMERG, is found in the Pacific Maritime $(\mathrm{H})$ coastal region. Similarly, the maximum length of dry spells (CDD) computed from IMERG estimates are in good agreement with EC-S and CaPA (Fig. 10) pooled from each ecozone. However, in the Prairie (F) with the most variable and longest run of mean number of dry days (37, 35, and 43 for EC-S, CaPA, and IMERG, respectively), IMERG tends to overestimate CDD by $\sim 6$ days.

The evaluation of IMERG to understand the expected error and accuracy of the estimates was not restricted only to its ability to reproduce the distributions of conditional heavy $P$ events, but we also made use of the binary extremal indices discussed in section $3 \mathrm{~b}$. The spatial distributions of FBIAS, EDS, SEDS, and SEDI in detecting heavy $P$ during the study period with respect to the reference datasets (EC-S and CaPA) is shown in Fig. 11. These nondegenerating, base-rate

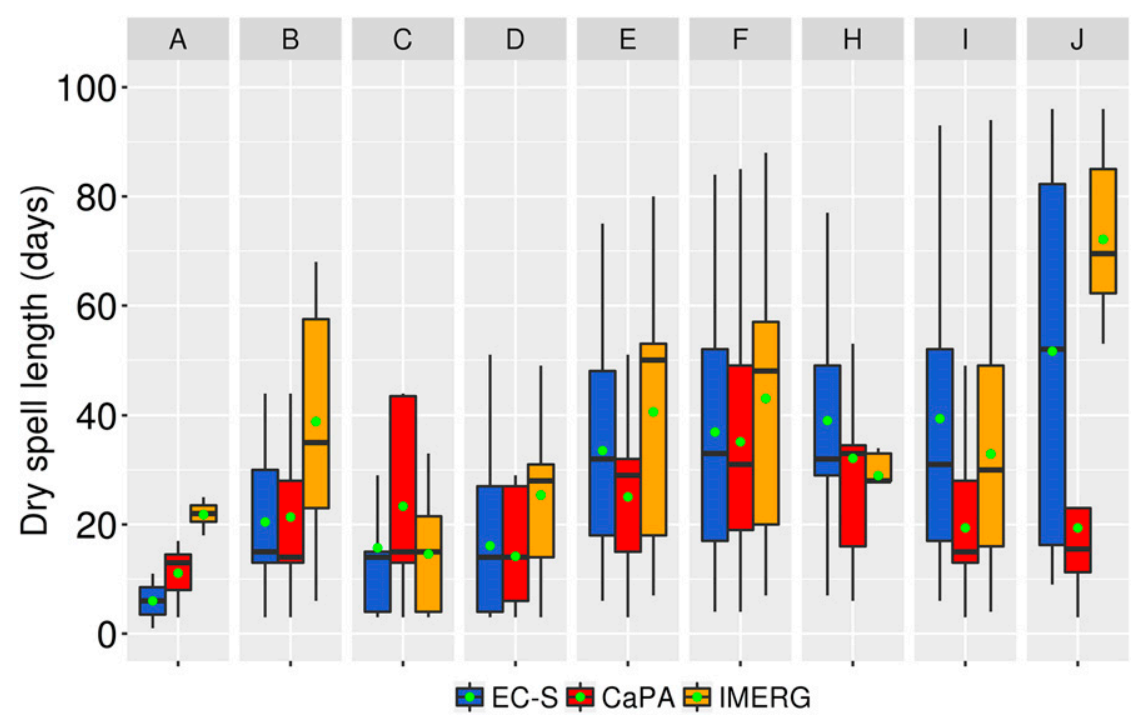

FIG. 10. As in Fig. 9, but for dry spell length (CDD). 

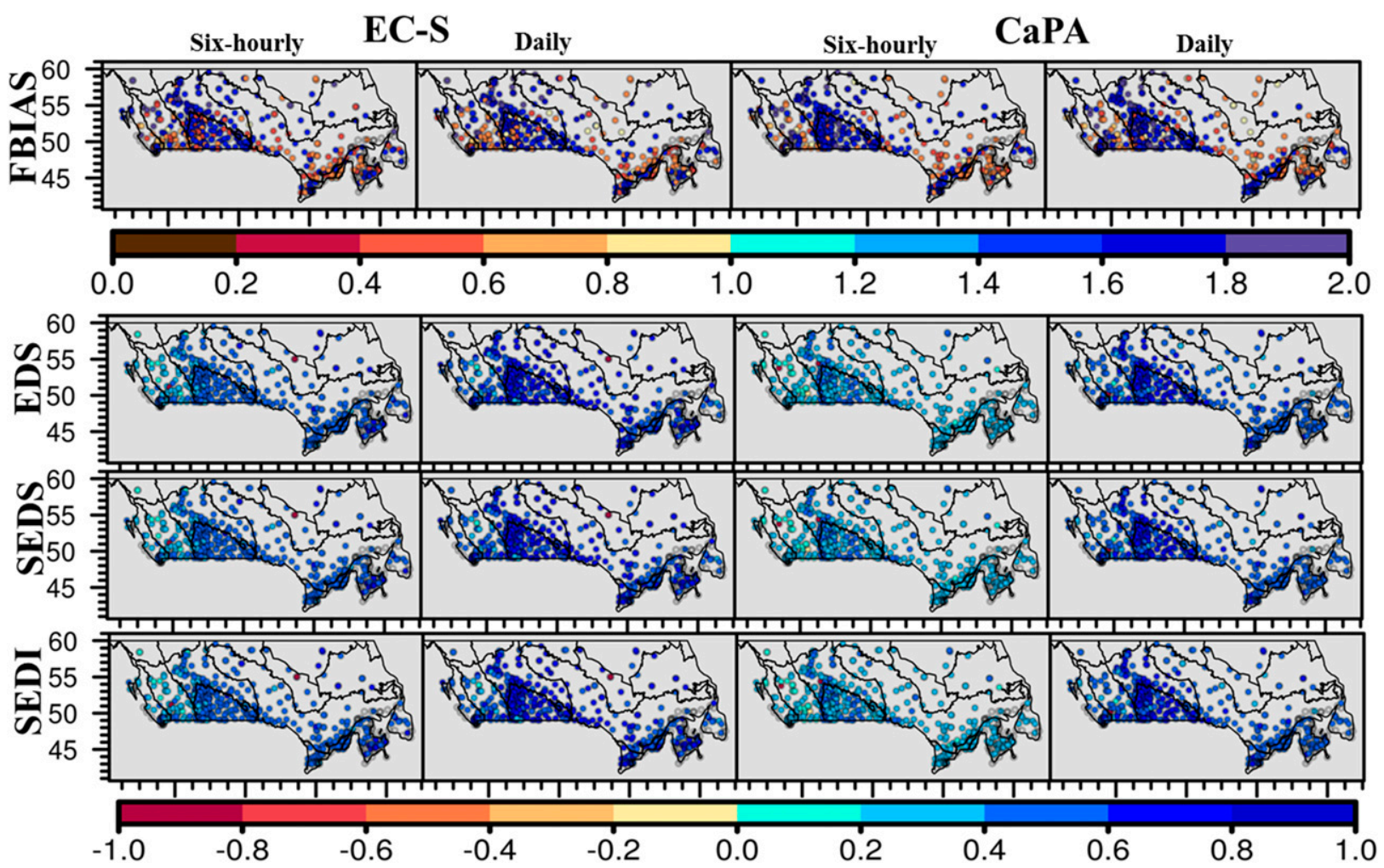

FIG. 11. The spatial pattern of contingency table extremal indices between observed ground-based products (EC-S and CaPA) and the satellite-derived product (IMERG) in detection of extreme $P$ above the ecozone-dependent 75 th percentile over southern Canada from 12 Mar 2014 to 31 Jan 2016. Note that every circle represents a gauge station.

independent, and asymptotically equitable indices measure the association between the estimated and observed rare binary events (Ferro and Stephenson 2011). FBIAS shows an alternating pattern of over- and underdetection of conditional heavy $P$ events relative to observed EC-S and CaPA data at both the 6-hourly and the daily time scales. Pockets of overdetection are concentrated over most of western Canada and along the east coast with some of the heavy $P$ regimes in the study region (see also Fig. S3 in the supplemental material). The EDS, SEDS, and SEDI share similar properties, as discussed in Ferro and Stephenson (2011). These indices indicate that IMERG performs reasonably well to detect heavy $P$ events over southern Canada at both time scales, except over large portions of the Montane Cordillera (I) and a few stations on the Prairie (F) ecozones where low skill is found. Again, IMERG performs better at the daily than the 6-hourly time scale and agrees relatively well with EC-S than CaPA. Over the Prairie, Boreal Plain, Mixedwood Plain, and Atlantic Maritime, IMERG depicts notably higher EDS, SEDS, and SEDI scores in the range of $0.4-0.9$ relative to observed data (EC-S and CaPA) at daily time scale. In Fig. S3 in the supplemental material, at both time scales, a grid-scale comparison indicated IMERG to have reduced performance in detecting $P$ events as judged by pockets of low skill areas over western Canada.

The foregoing analyses have revealed that, based on both CON and CAT metrics, IMERG can capture major regions of mean and heavy $P$, such as along the west and east coast of southern Canada. However, IMERG indicates a tendency toward slight overestimation at both low and high $P$ thresholds irrespective of the reference dataset. Similar findings showing IMERG to overestimate high $P$ intensities have been reported in other studies (e.g., Liu 2015; Prakash et al. 2016). Regionally, for both low and high $P$ thresholds, the most problematic ecozone is the Montane Cordillera (I). In Fig. 11, the extremal indices (EDS, SEDS, and SEDI) indicate that IMERG has relatively low to no skill at detecting heavy $P$ over this region, which may be attributed to a number of factors as follows. Foremost, as indicated by Fortin et al. (2015) and Wang and Lin (2015), gauge and radar networks are not only very sparse over this remote region, but are difficult to maintain such that the measurement errors may be as large as $50 \%-100 \%$ in cold months. The limited number of gauges used in this study could be a source of error in 
the analyses presented above. Moreover, as most biases are concentrated over the Rocky Mountains, it would be interesting to investigate the bias-topography relationship (e.g., Mei et al. 2014) during subsequent verification studies across Canada with the release of longer and global $\left(90^{\circ} \mathrm{N}-90^{\circ} \mathrm{S}\right)$ IMERG precipitation records. This kind of error analysis can be expected to give supplementary information and guidance to hydrologic studies regarding the uncertainties of satellite-derived $P$ estimates over complex mountainous basins (where in situ observations are limited) and for heavy $P$ events. More importantly, the occurrence of precipitation is dictated by the merged satellite estimates and the precipitation amount is weighted toward the gauge analysis and the gauge-adjusted merged satellite estimates. In areas of low gauge density, the gauge-adjusted merged satellite estimate is more heavily weighted. Second, IMERG is still at a very early stage (Day-1 currently), and thus the time span (from 12 March 2014 to 31 January 2016) of our study was very short. Moreover, gauge-based (EC-S) observations of $P$ are point measurements, while IMERG estimates are areal values resulting in a spatial scale issue (Ebert et al. 2007). The accuracy and precision of direct measurements (on the ground) and of derived estimates (from space measurements) are likely to be quite different. Therefore, caution should be exercised when comparing points to gridbox averages. Finally, the ultimate goal of this evaluation will be to use the IMERG product for surface hydrology in Canada, particularly at ungauged catchments. Future work will entail assessing the hydrologic utility of the IMERG product over this region of Canada while taking into consideration the challenges associated with such estimates (e.g., Gebremichael and Hossain 2010).

\section{Summary and conclusions}

The GPM Core Observatory was launched on 28 February 2014 by a joint effort of NASA and JAXA with the aim to provide the next generation of improved $P$ estimates at fine space-time scales. Future improvements of IMERG algorithms and utilization of GPMbased IMERG datasets in practical and theoretical applications rely on more rigorous assessments of errors and biases across different spatiotemporal scales. This study has provided an early and timely quantitative evaluation of error characteristics of the V03 IMERG Final Run product against ground-based observations (CaPA and EC-S) across southern Canada from 12 March 2014 to 31 January 2016. Several verification metrics (continuous and categorical) were used to quantify the satellite $P$ estimation performance in terms of $P$ totals and extremes. Based on the preliminary analyses presented in this study, the following main conclusions can be drawn.

1) In terms of the systematic regional variations of mean daily $P$, IMERG generally captured the spatial structure of $P$ over the study area. Particularly, the patterns and magnitudes in regions of heavy $P$, such as along the western coast (e.g., Pacific Maritime), and most of the eastern coast (e.g., Atlantic Maritime, parts of Boreal and Taiga Shields) are well reproduced if not of a tendency toward underestimation $\left(\sim 1.5 \mathrm{~mm} \mathrm{day}^{-1}\right)$ over the Montane and Boreal Cordillera when compared to CaPA.

2) The capability of IMERG to reproduce the distributional properties of observed $P$ when wet was also investigated at monthly time scale. IMERG agreed well with CaPA and EC-S over ecozones A, B, C, D, $\mathrm{E}, \mathrm{G}$, and $\mathrm{J}$, but with a tendency to underestimate larger $(>150 \mathrm{~mm})$ EC-S-based $P$ amounts in these ecozones. Overall, IMERG is relatively skillful on the east coast and most of the interior plains, but performance reduces over the Pacific Maritime (overestimation).

3) With higher Cor and lower biases, IMERG shows stronger linear association with CaPA than EC-S, and more so at the daily than the 6-hourly time scale. Regionally, more agreement is found over the Prairie, Boreal Plain, and much of the east and west coast (Cor $\sim 0.5-0.9$ ), unlike over much of the Boreal and Montane Cordillera as well as the Hudson Plain and Boreal and Taiga Shields (Cor $<0.5)$. However, larger biases of daily $P$ over the coastal maritime areas (ME $\sim 1.5-5 \mathrm{~mm}$ ) are noticeable.

4) Concerning the seasonal cycle, IMERG shows a better performance in the summer months with higher ETS $(\sim 0.25-0.5)$ and POD $(\sim 0.3-0.75)$ and relatively lower FAR (0-0.35) values compared to winter and spring months. Spatially, IMERG was able to reproduce reasonably the fraction of observed events (ETS). However, evaluation against CaPA (ETS 0.0-0.4) shows an improved performance, unlike against EC-S (ETS 0.0-0.2) at both time scales. In particular, higher POD $(\sim 0.8)$ and lower FAR $(\sim 0.2)$ can be found along the east and west coast in the case of CaPA at the daily scale compared to EC-S (POD $\sim 0.6$; FAR $\sim 0.3$ ). Regionally, IMERG weakly detects the $P$ events over the Prairie, Rocky Mountains, and the transition zones between the Boreal Shield and the Mixedwood Plain as judged by the high FAR values at the 6-hourly scale in the case of EC-S.

5) In relation to detecting $P$ extremes over southern Canada, generally, IMERG captures well the distribution 
of heavy $P$ amounts and observed wet/dry spell length distributions over most ecozones. Regionally, a better performance is found over the continental semiarid compared with relatively humid ecozones and mountainous areas where heavy $P$ amounts are overestimated. Based on binary extremal indices, FBIAS shows an alternating pattern of over- and underdetection of extreme $P$ at both the 6-hourly and the daily time scales. EDS, SEDS, and SEDI indicate that IMERG captures heavy $P$ well over southern Canada at both time scales, except over large portions of the Montane Cordillera and a few stations on the Prairie ecozone $(\mathrm{F})$ where low skill is found.

Finally, the present preliminary assessment of the IMERG product for reproducing various characteristics of observed $P$ totals and extremes across southern Canada has shown significant agreement with groundbased observations especially in the continental semiarid interior ecozones. However, some slight discrepancies were found over the mountainous and coastal regions characterized by heavy $P$ regimes. Apart from these, the results promise improved hydrologic utility of the post-real-time IMERG product. Furthermore, a more comprehensive statistical and hydrologic assessment of IMERG will require longer records and global coverage. We expect these improved IMERG estimates to be released later in 2017 (Huffman et al. 2015b) using retrospective processing of TMPA data since 1998. A comprehensive analysis will then be warranted using this long-period dataset.

Acknowledgments. Thanks are due to Kit Szeto from Environment and Climate Change Canada for providing access to observed precipitation data used in this study. Information on Canadian gauge stations used by GPCC was provided by Vincent Fortin and Bruce Davison of ECCC and Dr. Andreas Becker, Head Precipitation Monitoring Unit and GPCC. The IMERG data were provided by the NASA Goddard Space Flight Center's Precipitation Processing System (PPS), which develops and computes IMERG as a contribution to GPM. The data are archived at NASA GES DISC. Finally, we thank the editor and three anonymous referees for very detailed and useful comments which helped improve the quality of the analyses presented in the paper.

\section{REFERENCES}

Asong, Z. E., M. N. Khaliq, and H. S. Wheater, 2015: Regionalization of precipitation characteristics in the Canadian Prairie Provinces using large-scale atmospheric covariates and geophysical attributes. Stochastic Environ. Res. Risk Assess., 29, 875-892, doi:10.1007/s00477-014-0918-z.
,-- , and - 2016a: Multisite multivariate modelling of daily precipitation and temperature in the Canadian Prairie Provinces using generalized linear models. Climate Dyn., 47, 2901-2921, doi:10.1007/s00382-016-3004-z.

$[,-$, and $-2016 \mathrm{~b}$ : Projected changes in precipitation and temperature over the Canadian Prairie Provinces using the generalized linear model statistical downscaling approach. J. Hydrol., 539, 429-446, doi:10.1016/j.jhydrol.2016.05.044.

Bitew, M. M., M. Gebremichael, L. T. Ghebremichael, and Y. A. Bayissa, 2012: Evaluation of high-resolution satellite rainfall products through streamflow simulation in a hydrological modeling of a small mountainous watershed in Ethiopia. J. Hydrometeor., 13, 338-350, doi:10.1175/2011JHM1292.1.

Borchert, J. A., 1950: The climate of the central North American grassland. Ann. Assoc. Amer. Geogr., 40, 1-39, doi:10.1080/ 00045605009352020.

Bowman, K. P., 2005: Comparison of TRMM precipitation retrievals with rain gauge data from ocean buoys. J. Climate, $\mathbf{1 8}$, 178-190, doi:10.1175/JCLI3259.1.

Daley, R., 1991: Atmospheric Data Analysis. Cambridge University Press, $457 \mathrm{pp}$.

Ebert, E. E., and J. L. McBride, 2000: Verification of precipitation in weather systems: Determination of systematic errors. J. Hydrol., 239, 179-202, doi:10.1016/S0022-1694(00)00343-7.

, J. E. Janowiak, and C. Kidd, 2007: Comparison of near-realtime precipitation estimates from satellite observations and numerical models. Bull. Amer. Meteor. Soc., 88, 47-64, doi:10.1175/BAMS-88-1-47.

Ferro, C. A. T., and D. B. Stephenson, 2011: Extremal dependence indices: Improved verification measures for deterministic forecasts of rare binary events. Wea. Forecasting, 26, 699-713, doi:10.1175/WAF-D-10-05030.1.

Fortin, V., and G. Roy, 2011: The Regional Deterministic Precipitation Analysis (RDPA). Tech. Note, 7 pp. [Available online at http://collaboration.cmc.ec.gc.ca/cmc/cmoi/product_ guide/docs/lib/op_systems/doc_opchanges/technote_rdpa_e_ 20110406.pdf.]

_ C. Therrien, and F. Anctil, 2008: Correcting wind-induced bias in solid precipitation measurements in case of limited and uncertain data. Hydrol. Processes, 22, 3393-3402, doi:10.1002/ hyp.6959.

, G. Roy, N. Dobaldson, and A. Mahidjiba, 2015: Assimilation of radar quantitative precipitation estimation in the Canadian Precipitation Analysis (CaPA). J. Hydrol., 531, 296-307, doi:10.1016/j.jhydrol.2015.08.003.

Fritz, S., and H. Wexler, 1960: Cloud pictures from satellite TIROS I. Mon. Wea. Rev., 88, 79-87, doi:10.1175/1520-0493(1960)088<0079: CPFSTI $>2.0 . \mathrm{CO} ; 2$.

Gebremichael, M., and F. Hossain, Eds., 2010: Satellite Rainfall Applications for Surface Hydrology. Springer, 327 pp.

, W. F. Krajewski, M. Morrissey, D. Langerud, G. J. Huffman, and R. Adler, 2003: Error uncertainty analysis of GPCP monthly rainfall products: A data-based simulation study. J. Appl. Meteor. Climatol., 42, 1837-1848, doi:10.1175/ 1520-0450(2003)042<1837:EUAOGM > 2.0.CO;2.

Germann, U., G. Galli, M. Boscacci, and M. Bolliger, 2006: Radar precipitation measurement in a mountainous region. Quart. J. Roy. Meteor. Soc., 132, 1669-1692, doi:10.1256/qj.05.190.

Goodison, B. E., P. Y. T. Louie, and D. Yang, 1998: WMO solid precipitation intercomparison. Instruments and Observing Methods Rep. 67, WMO/TD-872, 212 pp. [Available online at https://www.wmo.int/pages/prog/www/IMOP/publications/ IOM-67-solid-precip/WMOtd872.pdf.] 
Gottschalck, J., J. Meng, M. Rodell, and P. Houser, 2005: Analysis of multiple precipitation products and preliminary assessment of their impact on Global Land Data Assimilation System land surface states. J. Hydrometeor., 6, 573-598, doi:10.1175/ JHM437.1.

Hogg, E. H., D. T. Price, and T. A. Black, 2000: Postulated feedbacks of deciduous forest phenology on seasonal climate patterns in the western Canadian interior. J. Climate, 13, 4229-4243, doi:10.1175/1520-0442(2000)013<4229:PFODFP > 2.0.CO;2.

Hong, Y., D. Gochis, J. T. Cheng, K. L. Hsu, and S. Sorooshian, 2007: Evaluation of PERSIANN-CCS rainfall measurement using the NAME event rain gauge network. J. Hydrometeor., 8, 469-482, doi:10.1175/JHM574.1.

Hossain, F., and G. J. Huffman, 2008: Investigating error metrics for satellite rainfall data at hydrologically relevant scales. J. Hydrometeor., 9, 563-575, doi:10.1175/2007JHM925.1.

Hou, A. Y., and Coauthors, 2014: The Global Precipitation Measurement mission. Bull. Amer. Meteor. Soc., 95, 701-722, doi:10.1175/BAMS-D-13-00164.1.

Huffman, G. J., R. F. Adler, M. M. Morrissey, D. T. Bolvin, S. Curtis, R. Joyce, B. McGavock, and J. Susskind, 2001: Global precipitation at one-degree daily resolution from multisatellite observations. J. Hydrometeor., 2, 36-50, doi:10.1175/ 1525-7541(2001)002<0036:GPAODD>2.0.CO;2.

- and Coauthors, 2007: The TRMM Multisatellite Precipitation Analysis (TMPA): Quasiglobal, multiyear, combined sensor precipitation estimates at fine scales. J. Hydrometeor., 8, 38-55, doi:10.1175/JHM560.1.

, D. T. Bolvin, D. Braithwaite, K. Hsu, R. Joyce, and P. Xie, 2014: NASA Global Precipitation Measurement Integrated Multi-satellitE Retrievals for GPM (IMERG). Algorithm Theoretical Basis Doc., version 4.4, 30 pp. [Available online at https://pps.gsfc.nasa.gov/Documents/IMERG_ATBD_V4.pdf.]

$-,-\longrightarrow,-,-$ C. Kidd, E. J. Nelkin, and P. Xie, 2015a: NASA Global Precipitation Measurement Integrated MultisatellitE Retrievals for GPM (IMERG). Algorithm Theoretical Basis Doc., version 4.5,30 pp. [Available online at http://pmm.nasa. gov/sites/default/files/document_files/IMERG_ATBD_V4.5.pdf.]

_ _ _ , and E. J. Nelkin, 2015b: Integrated Multi-satellitE Retrievals for GPM (IMERG) technical documentation. NASA/GSFC Code 612 Tech. Doc., 48 pp. [Available online at http://pmm.nasa.gov/ sites/default/files/document_files/IMERG_doc.pdf.]

Jolliffe, I. T., and D. B. Stephenson, Eds., 2003: Forecast Verification: A Practitioner's Guide in Atmospheric Science. Wiley, 240 pp.

Joyce, R. J., J. E. Janowiak, P. A. Arkin, and P. Xie, 2004: CMORPH: A method that produces global precipitation estimates from passive microwave and infrared data at high spatial and temporal resolution. J. Hydrometeor., 5, 487-503, doi:10.1175/1525-7541(2004)005<0487:CAMTPG > 2.0.CO;2.

Kidd, C., and G. Huffman, 2011: Global Precipitation Measurement. Meteor. Appl., 18, 334-353, doi:10.1002/met.284.

Kubota, T., and Coauthors, 2007: Global precipitation map using satellite-borne microwave radiometers by the GSMaP project: Production and validation. IEEE Trans. Geosci. Remote Sens., 45, 2259-2275, doi:10.1109/TGRS.2007.895337.

Lespinas, F., V. Fortin, G. Roy, P. Rasmussen, and T. Stadnyk, 2015: Performance evaluation of the Canadian Precipitation Analysis (CaPA). J. Hydrometeor., 16, 2045-2064, doi:10.1175/ JHM-D-14-0191.1.
Liu, Z., 2015: Comparison of Integrated Multisatellite Retrievals for GPM (IMERG) and TRMM Multisatellite Precipitation Analysis (TMPA) monthly precipitation products: Initial results. J. Hydrometeor., 17, 777-790, doi:10.1175/JHM-D-15-0068.1.

Maggioni, V., P. C. Meyers, and M. D. Robinson, 2016: A review of merged high resolution satellite precipitation product accuracy during the Tropical Rainfall Measuring Mission (TRMM) era. J. Hydrometeor., 17, 1101-1117, doi:10.1175/ JHM-D-15-0190.1.

Mahfouf, J.-F., B. Brasnett, and S. Gagnon, 2007: A Canadian Precipitation Analysis (CaPA) project: Description and preliminary results. Atmos.-Ocean, 45, 1-17.

Mei, Y., E. N. Anagnostou, E. I. Nikolopoulos, and M. Borga, 2014: Error analysis of satellite rainfall products in mountainous basins. J. Hydrometeor., 15, 1778-1793, doi:10.1175/ JHM-D-13-0194.1.

New, M., M. Todd, M. Hulme, and P. Jones, 2001: Precipitation measurements and trends in the twentieth century. Int. J. Climatol., 21, 1889-1922, doi:10.1002/joc.680.

Newman, A. J., and Coauthors, 2015: Gridded ensemble precipitation and temperature estimates for the contiguous United States. J. Hydrometeor., 16, 2481-2500, doi:10.1175/ JHM-D-15-0026.1.

Peterson, T. C., and Coauthors, 1998: Homogeneity adjustments of in situ atmospheric climate data: A review. Int. J. Climatol., 18, 1493-1517, doi:10.1002/(SICI)1097-0088(19981115)18:13<1493:: AID-JOC329>3.0.CO;2-T.

Prakash, S., A. K. Mitra, D. S. Pai, and A. AghaKouchak, 2016: From TRMM to GPM: How well can heavy rainfall be detected from space? Adv. Water Resour., 88, 1-7, doi:10.1016/ j.advwatres.2015.11.008.

Scaff, L., D. Yang, Y. Li, and E. Mekis, 2015: Inconsistency in precipitation measurements across the Alaska-Yukon border. Cryosphere, 9, 2417-2428, doi:10.5194/tc-9-2417-2015.

Schneider, U., A. Becker, P. Finger, A. Meyer-Christoffer, M. Ziese, and B. Rudolf, 2014: GPCC's new land surface precipitation climatology based on quality-controlled in situ data and its role in quantifying the global water cycle. Theor. Appl. Climatol., 115, 15, doi:10.1007/s00704-013-0860-x.

Sorooshian, S., K. L. Hsu, X. Gao, H. V. Gupta, B. Imam, and D. Braithwaite, 2000: Evaluation of PERSIANN system satellite-based estimates of tropical rainfall. Bull. Amer. Meteor. Soc., 81, 2035-2046, doi:10.1175/1520-0477(2000)081<2035: EOPSSE $>2.3 . C O ; 2$.

Tang, G., Y. Ma, D. Long, L. Zhong, and Y. Hong, 2016: Evaluation of GPM Day-1 IMERG and TMPA version-7 legacy products over mainland China at multiple spatiotemporal scales. J. Hydrol., 533, 152-167, doi:10.1016/j.jhydrol.2015.12.008.

Wang, X. L., and A. Lin, 2015: An algorithm for integrating satellite precipitation estimates with in situ precipitation data on a pentad time scale. J. Geophys. Res. Atmos., 120, 37283744, doi:10.1002/2014JD022788.

Wheater, H. S., and P. Gober, 2015: Water security and the science agenda. Water Resour. Res., 51, 5406-5424, doi:10.1002/ 2015WR016892.

Yong, B., D. Liu, J. J. Gourley, Y. Tian, G. J. Huffman, L. Ren, and Y. Hong, 2015: Global view of real-time TRMM Multisatellite Precipitation Analysis: Implication to its successor Global Precipitation Measurement mission. Bull. Amer. Meteor. Soc., 96, 283-296, doi:10.1175/BAMS-D-14-00017.1. 